\title{
AC 2007-1500: GROUP WORK ASSESSMENT IN ENGINEERING MANAGEMENT CLASSES
}

\section{Francisco Gamboa Valderrama, Universidad Nacional Experimental del Tachira}

\section{Bianey Ruiz, University of Tachira}

Bianey C. Ruiz Ulloa received her Ph.D. from the University of Nebraska -Lincoln in Industrial and Management Systems Engineering. She holds a M.S. degree in Industrial and Management Systems Engineering from the University of Nebraska-Lincoln and a M.B.A. and B.S. in Industrial Engineering from the Universidad Nacional Experimental del Táchira - Venezuela. She is currently an Associate Professor of Industrial Engineering at the Universidad Nacional Experimental del Táchira - Venezuela. Her research interests are teamwork, and organizational change. She worked for nine years for the manufacturing and service industry as an Industrial Engineer prior to her academic career.

\section{Dilia Alcalde, Universidad Nacional Experimental del Tachira}

Dilia M. Alcalde Avendaño received her Ph.D. and M.Ed. in Human Resource Development from the University of Nebraska -Lincoln. She holds a M.B.A. from the University of Nebraska Omaha and B.S. in Industrial Engineering from the Universidad Nacional Experimental del Táchira - Venezuela. She is currently an Aggregate Professor of Industrial Engineering at the Universidad Nacional Experimental del Táchira - Venezuela. Her research interests are organizational learning, and organizational development. She worked for manufacturing companies in the Human Resource area prior to her academic career. 


\section{GROUP WORK ASSESSMENT IN ENGINEERING MANAGEMENT CLASSES}

Statement of the problem

The Industrial Engineering Department at The National University of Tachira (UNET) is in charge of managing the engineering management area. Engineering management courses are offered to Industrial, Mechanical and Electronical engineering programs Faculty in this area uses the group work approach as learning strategy in the classroom.

Engineering faculty have found that using group work in their courses they achieve two main objectives: a) Students performance is better in comparison when students work individually; and b) students have the opportunity to face group work experience allowing them to learn how to work in group.

However, faculty is often faced with problems when they assess group performance because it is difficult to do assessments that reflect the actual performance of each member through the group experience without loosing the positive effect of working with groups. Usually assessment is reduced to an average of the group performance and to one evaluation at the end of the task. These types of assessments do not address and may even cause social loafing and/or inequity of work load.

For these reasons, it seems necessary to find an alternative assessment approach that addresses individual differences of group members and allows evaluation of individual contributions to the task through the group experience without losing the effect of working in groups.

\section{Background}

According to Forsyth (1999), a group is two or more interdependent individuals who influence one another through social interaction ${ }^{1}$. This definition implies that a group is characterized by a) being a social entity; b) has a common objective; c) there is interdependence between group members; and d) their interaction is a complex process.

Figure 1 shows the variables determine group members' behaviors. These variables are:

1. Clear and common objectives: Common objectives refer to the outcomes the group expects to achieve as reward of its performance. According to Garcia, Rodríguez, Díaz and Estrada $(1983)^{2}$, objectives should be developed by all group members in order to acquire acceptance and engagement of team members to the achievement of objectives. Group member's participation in developing objectives reduces anxiety, fears and emotional pressure on members, increasing the probability of accomplishing the objective.

2. Effective communication: According Castillero (2005), communication is a complex process of messages exchange with meaning for those participating in the process ${ }^{3}$. For communication to be effective, Robbins (2004) suggests that during the process it is 
necessary to maintain a) clear and comprehensible ideas which should have the same meaning for all group members; b) keep open communication where all information is available for all group members; c) avoid overloading information; and d) take into account group members emotional state to ensure a quality transmission of information ${ }^{4}$.

3. Clearly defined roles: Role is defined as an expected behavior pattern attributable to an individual as a member of a group (Robbins, 2004) ${ }^{4}$. Clear roles in a group contribute to improve coordination in developing the task and reduce the possibility of rising conflicts (Forsyth, 1999) ${ }^{1}$.

4. Interdependence: This variable establishes the intra-group connections as results of cohesion, membership satisfaction and cooperation. Cohesion is defined as the degree in which group members feel close to each other and motivate them to keep feeling in that way. Membership satisfaction refers to the engagement of the group members with the group because they feel they are part of the group and feel responsible for the group success or failure ${ }^{5,6}$. Finally, cooperation which is seen as the conviction of nobody achieve the goal if everybody do not go there, implies that group members should levering each other ion their abilities and skills to complement each other and achieve the group objective ${ }^{7}$.

5. Productive conflict resolution: Conflicts are a group of incompatible behaviors between two or more individuals in a group (Deutsh, 1973) ${ }^{8}$. Generally conflicts in groups arise because a member's need of defending a personal interest. To obtain a good group performance, conflict can not be avoided, because it is a natural consequence of human relationships, instead group members should manage conflicts to benefit from it by achieving their objectives and increasing cohesion and cooperation among them.

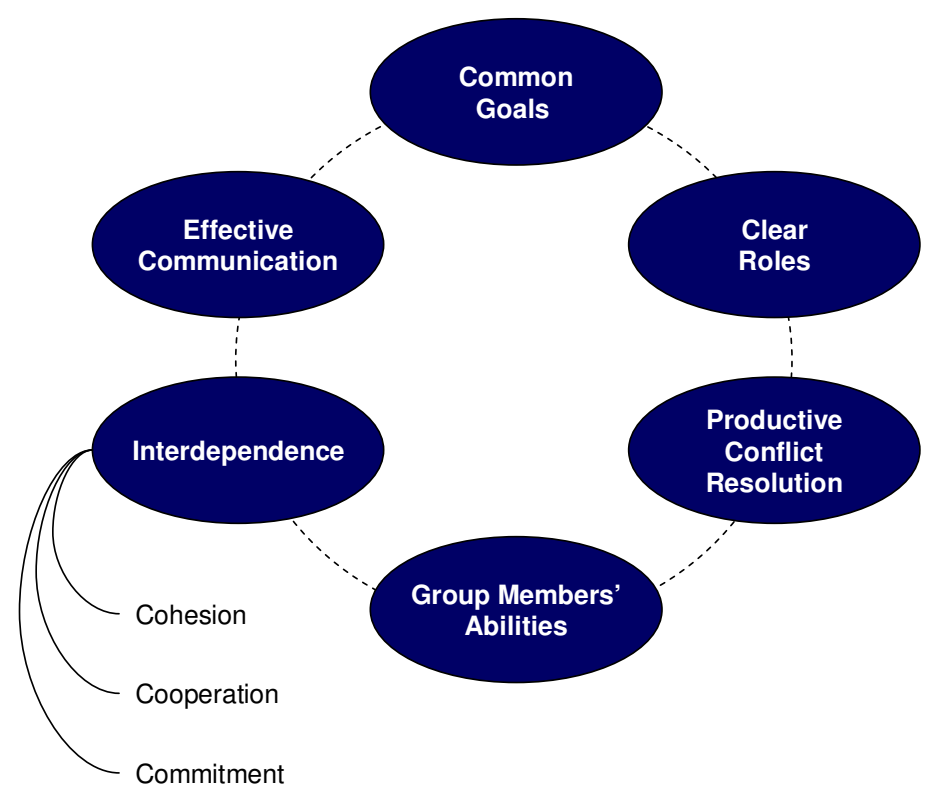

Figure 1. Group work performance variables 
Group work performance is defined as any action carried out by any individual in a group as consequence of the development of his or her task. Group work performance is measured during the whole work process to achieve group's objectives. Group work performance involves three important factors: a) Motivation toward the task and goals; b) availability of resources in quantity, quality and timeliness; and c) the individual capability to carry out the task ${ }^{4}$.

Regarding to performance assessment, this term is defined as the process of determining how individuals have accomplished the task assigned ${ }^{9}$. The performance assessment is a process of appreciation, estimation or judgment of a group of behaviors. Performance assessment should not be the final goal but the mean to improve performance results ${ }^{10}$. Performance assessment should be seen as a mechanism activated by all group members with the purpose of reviewing all activities they carry out too complete a task and from there take the corrective actions that allow them to improve their performance. Figure 2 shows the performance assessment process.

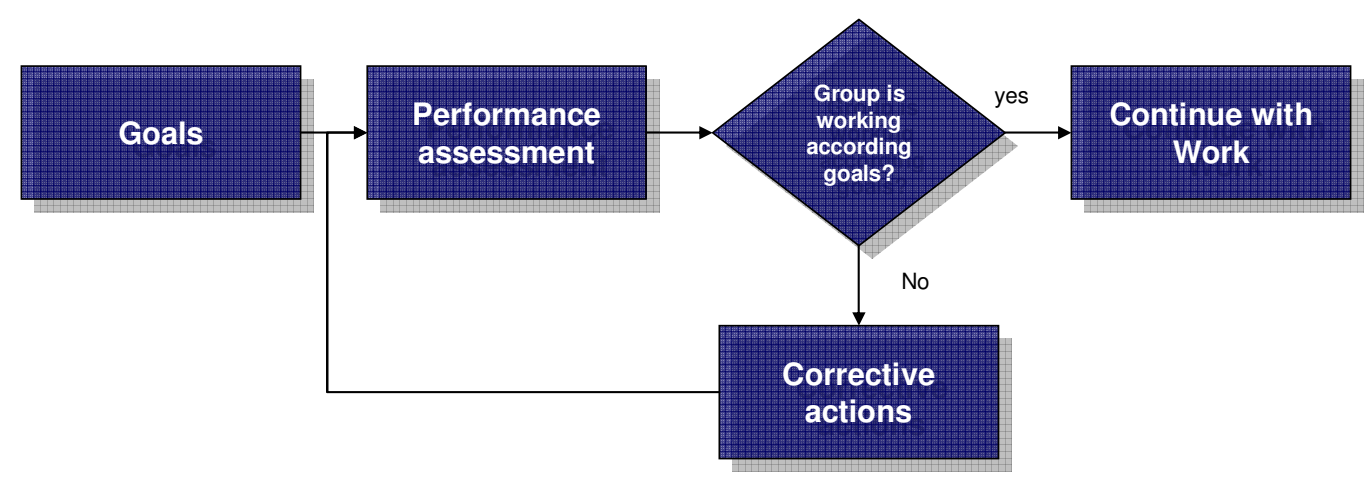

Figure 2. Performance assessment process

Proposed Group Work Assessment frame

Herrera and Robbiani (2006) developed an approach to assess teamwork. This approach has as premise the need for a continuous assessment of the team performance. The approach presents three phases of the assessment process. a) Assessment of activities previous to the development of the task, which intends to study the characteristics of the task and characteristics of team members; b) Assessment of activities during the task development, which assesses the progressive evolution of the task and individual performance; and c) assessment of activities following the development of the task, which measures consumer satisfaction and team performance $^{11}$.

For the purpose of this study, an adaptation of Herrera and Robiani's approach was done to measure group performance. This adaptation was necessary because the original approach was designed to measure performance of teams in the industry sector whereas this study addresses assessment of group performance in an academic setting. The adaptation of the assessment approach is shown in figure 3 as the group work assessment frame. 


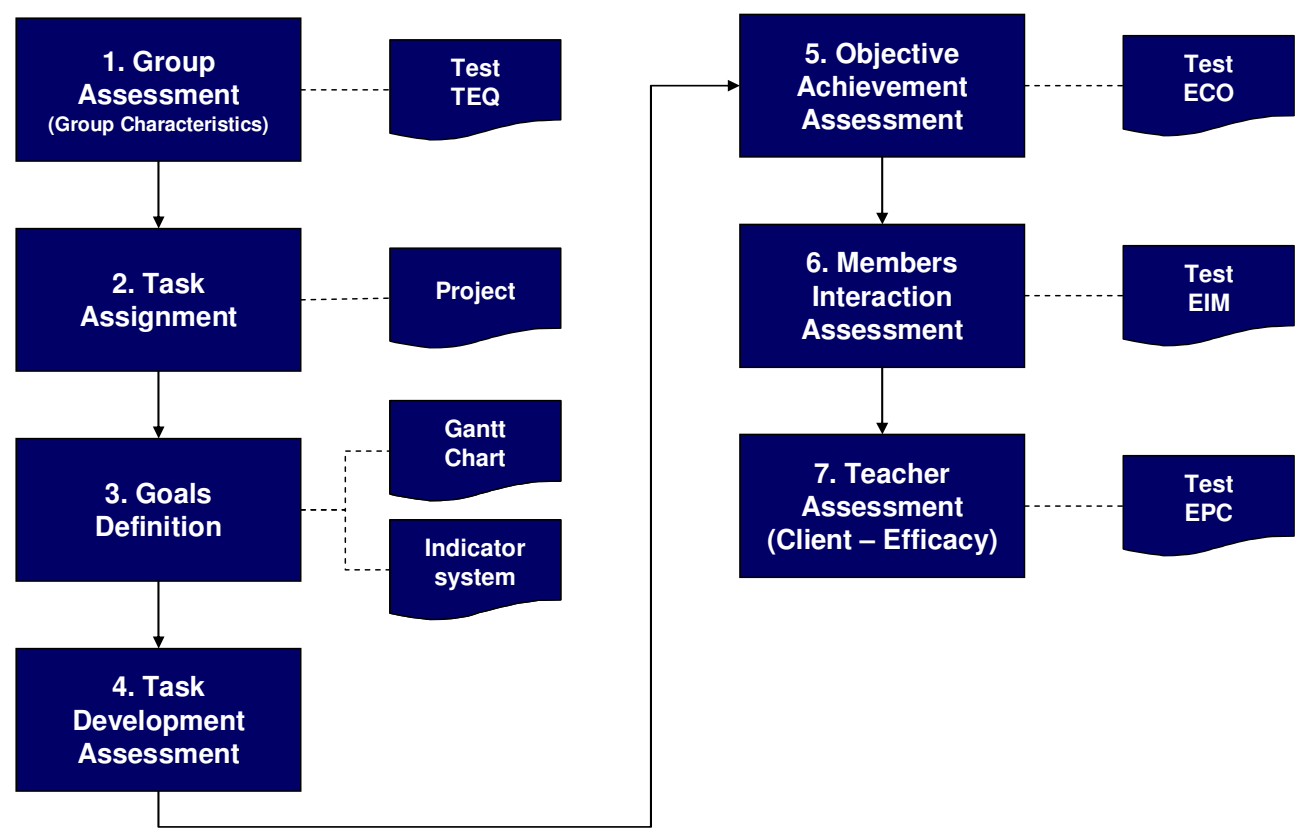

Figure 3. Group work assessment frame

The Group work assessment frame proposes seven activities previous, during and post development of the task. These activities are:

1. Previous to the development of the task:

a. Group evaluation: This activity has the objective to determine the group characteristics through individual evaluation to collect information related to strengths and weaknesses as group members. The Team Effective Questionnaire (TEQ) is suggested to use in this activity because this instrument allows for identifying an individual profile to become an effective team member. Because of the unit of study of groups instead of teams, in this experience, it is necessary to be cautious when analyzing results for groups.

b. Task assignment: In this second activity the task is assigned. The objective of the task should be described in writing and transmitted to all group members. In order to ensure that the task is appropriate for group work it is necessary to evaluate the task in the following dimensions: a) it should be divisible; b) Additive; and c) it should target to maximization or optimization.

c. Objectives definition: All group members participate in this activity. Group members develop a plan of action to coordinate the development of subtasks. In this step group members should pursuit: a) to build up one or more objectives leading to task completion, b) to develop activities leading to achieve objectives which will be displayed in a Gantt chart showing execution priorities, time, resources, and responsible, c) to develop indexes to help group members to follow the task progress 
2. During the development of the task:

a. Task development assessment: This activity take place during the period that activity is executed. The assessment is formative with the purpose of monitoring the development of the task and take corrective action during the process of making the task.

3. Post development of the task:

a. Objective achievement assessment: Once the task is completed the group should evaluate the level of achievement of objectives. This evaluation is done using the Objective Assessment Test (ECO) developed for this study.

b. Group members' interaction assessment: This assessment refers to an evaluation carried out by each group member on how they interact with each other to develop the task. They evaluate how each member manages conflict, communication, roles understanding and member engagement with the task. This evaluation is done using the Member's Interaction Assessment Test (EIM) developed for this study.

c. Teacher assessment: This activity consists in an evaluation carried out by the instructor in which assesses the accomplishment of objectives and the process of development the task. This evaluation is done using the Teacher Assessment Test (EPC) developed for this study.

Methodology and Results

With the purpose of proving the effectiveness of the proposed frame a quasi experimental design was used. Students of Industrial, Electronic and Mechanic engineering were faced with a specific task project. A total of 169 students were included in the sample, 61 in the control group and 108 in the experimental group.

To insure homogeneity among the control and experimental groups, the total points obtained in the diagnostic test (Group Evaluation) was used as discriminatory element. Using the TEQ it was possible to determine a characteristic profile for the subjects that formed part of each group under study. From this the conclusions in table 1 were obtained:

To test homogeneity among groups, a $\mathrm{t}$ - student test was used for independent samples (see table 1). From this, it was estimated with a $95 \%$ of confidence that there were not statistically significant differences between the average of points obtained in TEQ among the subjects in the control group and experimental group (Sig. $=0.048>\alpha / 2=0.025$ ). However, there is difference in the clarity of roles, accountable interdependence and attitude toward teamwork. Nevertheless this does not affect group homogeneity as is evidenced by the TEQ total points.

Once tested group homogeneity, students belonging to the experimental group were given feedback so that they will be aware of their group performance profile, identifying their weaknesses and strengths as work group members. 
Table 1

Team Effectiveness Questionnaire (TEQ) results

\begin{tabular}{|c|c|c|c|c|c|}
\hline \multirow[b]{2}{*}{ Variable } & \multirow[b]{2}{*}{ Sig. } & \multicolumn{2}{|c|}{$\begin{array}{c}\text { Control Group } \\
n=61\end{array}$} & \multicolumn{2}{|c|}{$\begin{array}{c}\text { Experimental Group } \\
n=108 \\
\end{array}$} \\
\hline & & $\mu$ & $\sigma$ & $\mu$ & $\sigma$ \\
\hline Mature communication & 0.253 & 45.70 & 13.65 & 48.03 & 10.72 \\
\hline Productive conflict resolution & 0.324 & 54.69 & 14.36 & 56.72 & 11.96 \\
\hline Clear objectives & 0.456 & 43.82 & 13.52 & 45.30 & 9.88 \\
\hline Common purpose & 0.545 & 50.44 & 11.14 & 51.42 & 9.43 \\
\hline Clear roles $(*)$ & 0.019 & 46.20 & 11.39 & 50.15 & 8.04 \\
\hline Psychological safety & 0.026 & 59.83 & 10.07 & 63.19 & 7.58 \\
\hline Accountable interdependence $(*)$ & 0.001 & 45.06 & 8.81 & 49.41 & 7.37 \\
\hline Attitude toward teamwork (*) & 0.017 & 40.91 & 9.96 & 44.45 & 7.42 \\
\hline Total score TEQ & 0.048 & 48.33 & 9.56 & 51.08 & 6.50 \\
\hline
\end{tabular}

(*) statistical significant at $\alpha=0.05$

Following, the groups were assigned a project where they were required to build an object (Task assignment), prior assessment of the capacities that students should have for the development of this activity. Specifications for the object were given as well as all limitations and resources that the groups had to achieve the task. After a brief session of questions and answers all groups began to work in the task.

Subjects in the control group began to work in the task as soon as the basic instructions were given. On the other hand subjects in the experimental group initiated the process with a Definition of Goals, developing as indicated in the methodology, a Gantt diagram and indicators. These mechanisms will allow the follow up of planned activities. Once the diagram and indicators were developed, each group initiated the construction of the object.

During the construction of the object the experimental work groups were doing Task

Development Assessment, since one of the group members was making pertinent calculations and was providing feedback to the whole group work. With this information in the majority of groups decision making was taken to adjust group performance according to what was planned using Gantt.

Once finished this process, the Phase Evaluation of post development of task was initiated with the Objective Achievement Assessment, using the ECO test. This test exhibit the following evaluation criteria: a)Estimated percentage of culmination, an estimated value of all the group members by consensus b) time of implementation of the project c) Grade of accomplishment of the required project parameters, using a 0-1 scale, and d) estimated percentage of use of resources. Applying the $\mathrm{t}$ student for independent samples and using the hypothesis for each of the variables, the results obtained are shown in table 2 bellow. 
Table 2

ECO Test Results

\begin{tabular}{|c|c|c|c|c|c|}
\hline \multirow[b]{2}{*}{ Factors } & \multirow[b]{2}{*}{ Sig. } & \multicolumn{2}{|c|}{ Group Control } & \multicolumn{2}{|c|}{ Experimental Group } \\
\hline & & $\mu$ & $\sigma$ & $\mu$ & $\sigma$ \\
\hline $\begin{array}{l}\text { Percentage on GW perception on } \\
\text { accomplishing the objective }\end{array}$ & 0.527 & 80.80 & 27.26 & 85.50 & 20.49 \\
\hline $\begin{array}{l}\text { Time used for accomplishing the } \\
\text { task (minutes) }\end{array}$ & 0.054 & 66.25 & 10.73 & 60.25 & 9.02 \\
\hline $\begin{array}{l}\text { Accomplishing requirements } \\
\text { (Scale: } 0 \text { - 1) }\end{array}$ & 0.170 & 1.26 & 0.09 & 1.31 & 0.14 \\
\hline $\begin{array}{l}\text { Percentage of resources used for } \\
\text { accomplishing the task }\end{array}$ & 0.060 & 87.39 & 11.02 & 81.28 & 11.02 \\
\hline
\end{tabular}

With 95\% confidence it can be said that there are statistically significant differences between the measures for control and experimental groups in each factor that measured by ECO test. This difference is favorable for the experimental group since the experimental work group:

1. Perceived achievement of objective a $4.70 \%$ higher than the control group.

2. In average, used 6 minutes less in the task implementation than the control group, which represents a $9.05 \%$ of the time used by the control group.

3. Accomplished with 0.05 more units the task requirements than the control group (scale 0 $-1)$ and,

4. Used in average a $6.11 \%$ fewer resources than the control group.

The next step of the method was the Assessment of Group Member Interactions. To do this the test EIM was used. This test measures the perception that members of a group have about their group interactions. It is segmented in 8 factors: a) common objectives; b) Effective communication; c) role clarity; d) Productive conflict resolution; e) group cohesiveness; f) group cooperation; g) commitment with objective accomplishment; h) members capacities to achieve the task. With the application of the EIM test the results shown in table 3 were obtained.

From the assessment of group members it can be concluded with $95 \%$ confidence that there are not statistically significant differences in member of WG interactions for both groups. However, it is observed that for subjects in the experimental group a decrease in the values for factors effective communication, commitment, cooperation and role clarity, being this, a statistically significant difference favorable to the values for the control group. 
Table 3

EIM Test scores

\begin{tabular}{|c|c|c|c|c|c|}
\hline \multirow[b]{2}{*}{ Factors } & \multirow[b]{2}{*}{ Sig. } & \multicolumn{2}{|c|}{ Control Group } & \multicolumn{2}{|c|}{ Experimental Group } \\
\hline & & $\mu$ & $\sigma$ & $\mu$ & $\sigma$ \\
\hline Common objectives $(*)$ & 0.019 & 4.5943 & 0.5376 & 4.3391 & 0.6963 \\
\hline Effective communication & 0.037 & 4.6339 & 0.5760 & 4.4217 & 0.6407 \\
\hline Clear roles & 0.446 & 4.5385 & 0.7266 & 4.4435 & 0.7515 \\
\hline Productive conflict resolution $(*)$ & 0.024 & 4.6887 & 0.6521 & 4.4336 & 0.6830 \\
\hline Cohesion $(*)$ & 0.000 & 4.6786 & 0.4808 & 4.3391 & 0.7301 \\
\hline Cooperation & 0.739 & 4.7547 & 0.5853 & 4.7217 & 0.6004 \\
\hline Membership satisfaction & 0.094 & 4.7381 & 0.4604 & 4.6029 & 0.5066 \\
\hline Members capabilities $(*)$ & 0.002 & 4.5566 & 0.5773 & 4.2261 & 0.7558 \\
\hline Total group interaction $(*)$ & 0.005 & 4.6565 & 0.4214 & 4.4367 & $\mathbf{0 . 5 0 3 4}$ \\
\hline
\end{tabular}

$(*)(*)$ statistical significant at $\alpha=0.05$

And finally, the Faculty Evaluations were conducted. To do this the EPC test was used. This test contains basic criteria of Quality, level of satisfaction with the product, and time effectiveness. From this, results in table 4 were obtained.

Table 4

EPC Test scores

\begin{tabular}{lccccc} 
& & \multicolumn{2}{c}{ Control Group } & \multicolumn{2}{c}{ Experimental Group } \\
\cline { 3 - 6 } & Sig. & $\mu$ & $\sigma$ & $\mu$ & $\sigma$ \\
\hline Faculty evaluation & 0.00005 & 3.5250 & 0.3493 & 4.1143 & 0.5563 \\
\hline
\end{tabular}

(*) statistical significant at $\alpha=0.05$

From table 4 it can be concluded with $95 \%$ confidence that there are statistically significant differences between the average points given by faculty to the products generated by the control and experimental WG, being favorable the points for the work groups in the experimental group.

\section{Conclusions}

The group work assessment approach proposed in this study allows evaluation the process of work groups from different perspectives. First, the group members' auto evaluation allows them to reflect on their weaknesses and strengths to contribute to the development of the task. Second, the co-evaluation gives group members the opportunity to evaluate their interactions and how these interactions have influence on their group work. Finally, the teacher assessment, as an 
external evaluator of group performance, allows determining deviation from objectives during the process of group working and contributes, through on time feedback, to improve the process of task development. Furthermore, the approach gives group members tools for organizing; planning and evaluating actions they will follow to complete the task effectively.

Finally, from the results it is seen that the approach contribute to motivate group members and organize group members efforts to achieve the task. However, the approach does not contribute with the development of group competencies for building group work.

Bibliography

1. Forsyth, D. (1999) Group Dynamics (3th ed.) Belmont, CA: International Thomson Publishing Company

2. García M., Rodríguez C., Díaz J. \& Estrada J. (1983). El trabajo en equipo productividad y calidad de vida en el trabajo. Madrid, España: Fondo Educativo Interamericano

3. Castillero, Y. (2005) Comunicarse eficazmente un reto para todos. Retrieved: January 03, 2006 From: http://www.gestiopolis.com/Canales4/rrhh/comureto.htm

4. Robbins, S (2004) Organizational Behavior (10th ed.) México: Pearson - Prentice may

5. Socorro, F. (2005) ¿Identificación o compromiso? La diferencia entre querer y tener que hacer el trabajo Retrieved: January 03, 2006. From: http://www.gestiopolis.com/canales/derrhh/articulos/52/diferencia.htm

6. Premolí, M. (2005) Las cinco “C” para el trabajo en equipo. Retrieved: January 03, 2006. From:

http://www.competir.com/es/corporaciones/capacitacion/articulos.asp?id=40085\&TipoCont =6\&path=AREA\%20DE\%20NEGOCIOS\%20:\%20Recursos\%20Humanos

7. Ballenato, $\mathrm{G}(\mathrm{s} / \mathrm{f})$ Trabajo en equipo dinámica y participación en los grupos. Retrieved: January 03, 2006. From: http://www.cop.es/colegiados/m13106/images/FichaT\%C2\%BAEweb.pdf

8. Deutsh, M. (1973) La Resolución del Conflicto. Unpublished document, Instituto de Estudios Superiores de Administración (IESA) Caracas, Venezuela

9. Werther, W.\& Davis, K. (1989) Administración de personal y recursos humanos. México: Mc Graw-Hill

10. Chiavenato, A (1983) Administración de Recursos Humanos. México. McGraw-Hill

11. Herrera, E. \& Robbiani, R. (2006) Evaluación del Desempeño de los Equipos de Trabajo. Unpublished document, Universidad Nacional Experimental del Táchira. San Cristóbal, Venezuela. 